\title{
Augmenting major histocompatibility complex class I expression by murine tumors in vivo enhances antitumor immunity induced by an active immunotherapy strategy
}

\author{
Robert E. Merritt, MD
}

Reiko E. Yamada, BA

Ronald G. Crystal, MD

Robert J. Korst, MD

From the Department of Cardiothoracic Surgery, Weill Medical College of Cornell University, New York, NY.

These studies were supported, in part, by the Will Rogers Memorial Fund, Los Angeles, Calif; Gen Vec, Inc., Gaithersburg, Md; and grants from The Thoracic Surgery Foundation for Research and Education (R.J.K.) and the American Lung Association (R.J.K.).

Read at the Eighty-third Annual Meeting of The American Association for Thoracic Surgery, Boston, Mass, May 4-7, 2003.

Received for publication May 1, 2003; revisions requested July 16, 2003; accepted for publication Sept 17, 2003.

Address for reprints: Robert J. Korst, MD, Assistant Professor of Cardiothoracic Surgery, Weill Medical College of Cornell University, Department of Cardiothoracic Surgery, M404, 525 East 68th Street, Box 110, New York, NY 10021 (E-mail: rjk2002@med.cornell.edu).

J Thorac Cardiovasc Surg 2004;127:355-64 $0022-5223 / \$ 30.00$

Copyright () 2004 by The American Association for Thoracic Surgery

doi:10.1016/j.jtcvs.2003.09.007
Objective: Tumors down-regulate major histocompatibility complex class I expression, escaping recognition by the cellular immune response. We hypothesized that augmentation of tumor cell class I expression by interferon-gamma would enhance the cellular antitumor immune response and cure rate of an active immunotherapy strategy.

Methods: B16.F10 tumor cells were exposed to interferon-gamma in culture, and class I expression was quantified using flow cytometry. Syngeneic mice bearing established tumors were injected with interferon-gamma (5000 U, intraperitoneal), and class I expression was assessed using immunohistochemistry. Tumor-specific cytotoxic $\mathrm{T}$ lymphocytes were induced in mice by an intratumoral injection of AdCD40L $\left(5 \times 10^{10}\right.$ particles), an adenovirus gene transfer vector-based immunotherapy strategy previously demonstrated to augment cellular antitumor immunity. A conjugate-formation assay and the enzyme-linked immunospot assay were used to evaluate the binding and activation of cytotoxic $\mathrm{T}$ lymphocytes, respectively. Interferon-gamma was administered to tumor-bearing mice concomitantly with intratumoral AdCD40L. End points measured included the frequencies of cytotoxic $\mathrm{T}$ lymphocytes using the enzyme-linked immunospot assay, tumor size, and mouse survival. The role of class I expression was further evaluated by monoclonal antibody blockade in both in vitro and in vivo experiments.

Results: B16.F10 cells exposed to interferon-gamma expressed significantly more class I, both in vitro and in vivo, and were able to bind to and activate cytotoxic $\mathrm{T}$ lymphocytes more efficiently than untreated cells. Cytotoxic T-lymphocyte frequencies, tumor regression, and the cure rate induced by $\mathrm{AdCD} 40 \mathrm{~L}$ were augmented by the addition of a single dose of interferon-gamma in tumor-bearing mice. These in vitro and in vivo effects of interferon-gamma were attenuated by class I monoclonal antibody blockade.

Conclusions: Up-regulation of class I expression using interferon-gamma enhances the cellular antitumor immune response and cure rate of AdCD40L, an active immunotherapy strategy. This approach may be useful for human tumors that lack class I expression.

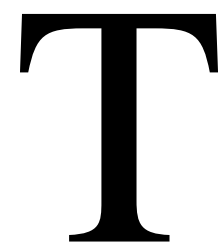

he major histocompatibility complex (MHC) represents a collection of genes encoding proteins that are integral in distinguishing between self and nonself by the immune system. ${ }^{1-3}$ Class I MHC molecules are glycoproteins expressed ubiquitously by most nucleated cells and have been shown to be necessary for the presentation of antigens manufactured by these cells to naive CD8 $+\mathrm{T}$ lymphocytes. ${ }^{1-3}$ As such, class I molecules are thought to play a vital role in cell-mediated immunity against virally infected cells as well as tumors. ${ }^{3}$ One mechanism by which 
tumor cells are thought to escape the antitumor immune response is by attenuating their expression of MHC class I molecules. For example, class I is only inconsistently expressed by human lung cancer cells in vitro and in vivo. ${ }^{4-8}$

Many agents, including some cytokines and chemotherapeutics, have been shown to enhance MHC class I expression by tumor cells. ${ }^{8-10}$ One of the most well-characterized modulators in this regard is interferon-gamma (IFN $\gamma$ ), which has been shown to enhance class I expression in multiple human lung cancer cell lines. ${ }^{8,10}$ Despite this, a paucity of data exists concerning the modulation of class I molecule expression by IFN in established tumors in vivo. In our laboratory, we have developed active antitumor immunotherapy strategies that are dependent on the generation of tumor-specific, cellular immunity. ${ }^{11,12}$ One of these strategies has involved the transduction of established murine tumors with an adenovirus (Ad) gene transfer vector containing the gene for CD40 ligand (AdCD40L). ${ }^{11}$ However, these strategies have been clearly less effective in murine tumors that express low levels of MHC class I. ${ }^{11,12}$ Given that IFN $\gamma$ enhances the expression of class I by tumor cells in vitro, ${ }^{8,10}$ we hypothesized that administration of IFN $\gamma$ to mice bearing established tumors would up-regulate MHC class I expression by the tumors and, subsequently, enhance tumor-specific cellular immunity induced by AdCD40L. In this regard, the data show that (1) exposure of B16.F10 tumor cells to IFN $\gamma$ augments MHC class I expression in vitro and in vivo and enhances tumor cell binding to tumorspecific cytotoxic T lymphocytes (CTLs); (2) treatment of tumor-bearing mice with a single dose of IFN $\gamma$ results in more efficient generation of tumor-specific CTLs by an active immunotherapy strategy (AdCD40L); (3) exposure of B16.F10 tumor cells to IFN $\gamma$ enhances tumor-specific CTL activation in coculture; (4) a single dose of IFN $\gamma$ administered to tumor-bearing mice augments the antitumor activity and cure rate of an established immunotherapy strategy (AdCD40L); and (5) these synergistic effects of IFN $\gamma$ are attenuated by the administration of an anti-MHC class I monoclonal antibody (MAb).

\section{Materials and Methods \\ Mice}

Female wild-type C57BL/6 (H-2b) mice (6-8 weeks old) were obtained from Jackson Laboratories (Bar Harbor, Me). The mice were housed under specific pathogen-free conditions and treated according to the National Institutes of Health guidelines. All animal procedures were approved by the Institutional Animal Care and Use Committee.

\section{Cell Culture}

B16.F10 (H-2b) and Lewis Lung Carcinoma (LLC; H-2b) are syngeneic to $\mathrm{C} 57 \mathrm{BL} / 6$ mice. The cell lines were obtained from American Type Culture Collection (ATCC, Manassas, Va; catalog no. CRL 6475) and maintained in complete Dulbecco's modified
Eagle's medium (DMEM; $10 \%$ fetal bovine serum, $100 \mu \mathrm{g} / \mathrm{mL}$ streptomycin, and $100 \mathrm{U} / \mathrm{mL}$ penicillin) at $5 \% \mathrm{CO}_{2}$ and $37^{\circ} \mathrm{C}$.

\section{Adenovirus Vectors}

All gene transfer vectors used in this study are replication-deficient, E1-, E3-vectors based on the adenovirus serotype 5 (Ad5) genome. AdCD40L contains an expression cassette with the murine CD40L cDNA under the control of the cytomegalovirus early-immediate promoter/enhancer. ${ }^{11}$ AdNull, a control vector, is similar to AdCD40L but contains an empty expression cassette. ${ }^{13}$ Adenovirus vectors were propagated in human embryonic kidney cells (293 cells; ATCC) and purified through 2 cesium chloride gradient ultracentrifugations as previously described. ${ }^{14,15}$ The viral particle concentration was determined by ultraviolet absorbance at $260 \mathrm{~nm} .^{16}$

\section{Quantification of MHC Class I Expression in Vitro}

To determine whether IFN $\gamma$ up-regulates the expression of class I by B16.F10 cells in vitro, 50\% confluent B16.F10 cells were exposed to $500 \mathrm{U} / \mathrm{mL}$ of recombinant murine IFN $\gamma$ (rmIFN $\gamma$; Roche Diagnostics, Mannheim, Germany) for 48 hours in complete DMEM at $37^{\circ} \mathrm{C}$. The cells were harvested, washed 3 times with phosphate-buffered saline (PBS), and stained with either fluorescein isothiocyanate (FITC)-conjugated mouse anti-mouse $\mathrm{H}-2 \mathrm{~Kb}$ MAb or FITC-mouse immunoglobulin G (IgG) $2 \kappa$ isotype control antibody (Pharmingen, San Diego, Calif). The cells were then subjected to flow cytometric analysis (FACStar, Becton Dickinson, San Jose, Calif) to determine $\mathrm{H}-2 \mathrm{~Kb}$ MHC class I expression.

\section{Modulation of MHC Class I Expression in Vivo}

To assess the ability of IFN $\gamma$ to enhance MHC class I expression by established tumors in vivo, $5 \times 10^{5}$ B16.F10 cells were injected subcutaneously in the right flanks of wild-type C57BL/6 mice. When the tumors were approximately 45 to 50 $\mathrm{mm}^{2}$ (day 8), a single subtherapeutic dose (5000 U) of rmIFN $\gamma$ was administered into the peritoneal cavity (IP). The animals were killed and the tumors harvested 24 or 48 hours after rmIFN $\gamma$ injection. Untreated tumor-bearing mice served as negative controls. The tumors were resected from the right flank, embedded in Optimal Cutting Temperature compound (Sakura Finetek, Torrance, Calif), snap-frozen in a 2-methylbutane/dry ice bath, and prepared as $10-\mu \mathrm{m}$ frozen sections. The tumor sections were blocked with $5 \%$ goat serum (Sigma Chemical Co, St Louis, Mo) for 20 minutes, washed with PBS, and incubated with a biotin-conjugated mouse anti-mouse $\mathrm{H}-2 \mathrm{~Kb}$ MAb (Pharmingen) for 2 hours. The slides were then washed with PBS and incubated with avidin-horseradish peroxidase solution (Pharmingen) for 30 minutes. After further washing with PBS, the tumor sections were exposed to 3,3'-diaminobenzidine chromagen substrate (Pharmingen) for 10 minutes, washed with PBS, and counterstained with hematoxylin. Following 3 washes with deionized water, the tumor sections were rehydrated with $95 \%$ ethanol and mounted for light microscopy.

\section{Generation and Purification of Tumor-Specific Cytotoxic T Lymphocytes}

To generate activated tumor-specific CD8 + CTLs, $5 \times 10^{5}$ B16.F10 cells were injected into the right flanks of C57BL/6 mice. 
When the tumors reached 45 to $50 \mathrm{~mm}^{2}$, AdCD40L $\left(5 \times 10^{10}\right.$ particle units in $100 \mu \mathrm{L}$ PBS) was injected intratumorally. Seven days after AdCD40L administration, the mice were killed and their spleens were harvested. The spleens were minced with a razor and passed through a $100-\mu \mathrm{m}$ nylon mesh filter. The resulting splenocyte suspensions were treated with ACK Lysing Buffer (Biosource International, Camarillo, Calif) to lyse red blood cells and washed with PBS. The Spinsep murine cell enrichment procedure (Stem Cell Technologies, Vancouver, BC, Canada) was then performed to purify CD8 $+\mathrm{T}$ lymphocytes according to the manufacturer's instructions. Flow cytometic analysis indicated that $90 \%$ of the purified splenocytes were CD8 $+\mathrm{T}$ lymphocytes (data not shown).

\section{Cytotoxic T-Lymphocyte Binding Assay}

To assess the ability of CTLs to bind to target cells, a conjugateformation binding assay was performed as described by Nakamura and colleagues ${ }^{17}$ and Noguchi and colleagues. ${ }^{18}$ B16.F10 cells were cultured in either complete DMEM or complete DMEM with the addition of $500 \mathrm{U} / \mathrm{mL}$ of $\mathrm{rmIFN} \gamma$ for 48 hours. The cells were collected using trypsin-ethylenediaminetetraacetic acid and washed 3 times with PBS. The B16.F10 tumor cells were stained with $1 \mu \mathrm{g} / \mathrm{mL}$ of hydroethidine (Molecular Probes, Junction City, Ore) for 1 hour at $37^{\circ} \mathrm{C}$. The purified CD8 $+\mathrm{T}$ lymphocytes from AdCD40L-treated mice were stained with $1 \mu \mathrm{g} / \mathrm{mL}$ of sulfofluoresceindiacetate (Molecular Probes) for 1 hour at $37^{\circ} \mathrm{C}$. The stained $\mathrm{CD} 8+\mathrm{T}$ lymphocytes were then cocultured with either rmIFN $\gamma$-exposed B16.F10 cells or untreated B16.F10 cells at a 1:1 ratio $\left(8 \times 10^{4}\right.$ cells each) for 15 minutes at $37^{\circ} \mathrm{C}$. Purified mouse anti-mouse $\mathrm{H}-2 \mathrm{~Kb} \mathrm{MAb}(4 \mu \mathrm{g}$; Pharmingen) was added to selected wells to assess the role of MHC class I in CTL binding. Binding of CD8 $+\mathrm{T}$ lymphocytes and B16.F10 cells was then quantified using 2-color flow cytometry (FACStar; Becton Dickinson). The percentage of bound CD8 + cells was calculated as follows: Binding $(\%)=$ (no. of green-red double positive counts)/ (total no. of green positive counts) $\times 100$.

\section{IFN $\gamma$ Enzyme-Linked Immunospot Assay}

To quantify the frequencies of tumor-specific CTLs, the enzymelinked immunospot (ELISPOT) assay was employed. The ELISPOT assay is a sensitive and reproducible assay for the functional and quantitative determination of the proportion of tumor-specific CTLs $^{19,20}$ and has become a standard method for the determination of CTLs in immunotherapy clinical trials. ${ }^{20}$ Each spot observed in the assay represents a single, tumor-specific, activated $\mathrm{T}$ lymphocyte, detected by its ability to secrete IFN $\gamma$.

Target cell preparation. Target cells consisted of B16.F10 cells exposed to rmIFN $\gamma(500 \mathrm{U} / \mathrm{mL} ; 48$ hours $)$, untreated B16.F10 cells, or the syngeneic negative control cell line, LLC. Prior to their use in the ELISPOT assay, target cells were washed with PBS and treated with $100 \mu \mathrm{g} / \mathrm{mL}$ of mitomycin $\mathrm{C}$ (Sigma) at $37^{\circ} \mathrm{C}$ for 1 hour. The tumor cells were then washed in complete ELISPOT medium (RPMI 1640 supplemented with $10 \%$ fetal bovine serum, $100 \mu \mathrm{g} / \mathrm{mL}$ streptomycin, $100 \mathrm{U} / \mathrm{mL}$ penicillin, $10 \mathrm{mmol} / \mathrm{L} \mathrm{N}-2-$ hydroxyethylpiperazine-N-2-ethanesulfonic acid buffer, $1 \mathrm{mmol} / \mathrm{L}$ L-glutamine, and $5 \times 10^{-5} \mathrm{~mol} / \mathrm{L} \beta$-mercaptoethanol) and resuspended at $10^{6}$ cells $/ \mathrm{mL}$.

Effector cell preparation. Effector cells for use in the ELISPOT assay were generated using the in vivo tumor model previ- ously described (see Generation and Purification of Tumor-Specific Cytotoxic T Lymphocytes). Four groups of effector cells were prepared, which included total splenocytes from (1) AdCD40Ltreated mice, (2) AdCD40L-treated mice that also received a concomitant IP injection of rmIFN $\gamma$ (5000 U), (3) AdNull-treated mice, and (4) PBS-treated mice. Unlike the preparation for the binding assay, CD8 $+\mathrm{T}$ cells were not purified from total splenocytes for use in the ELISPOT assay, with the goal of preserving the presence of antigen-presenting cells. The splenocytes were resuspended in complete ELISPOT medium at a concentration of $8 \times$ $10^{6}$ cells $/ \mathrm{mL}$.

ELISPOT assay. Ninety-six-well multiscreen-IP membrane plates (Millipore, Bedford, Mass) were coated with $100 \mu \mathrm{L}$ of a rat anti-mouse IFN $\gamma$ MAb (Mabtech, Cincinnati, Ohio) at a concentration of $10 \mu \mathrm{g} / \mathrm{mL}$ overnight at $4^{\circ} \mathrm{C}$. The plates were blocked with $150 \mu \mathrm{L}$ of complete ELISPOT medium and incubated for 2 hours at $37^{\circ} \mathrm{C}$. The blocking buffer was decanted and $4 \times 10^{5}$ splenocytes $/ 50 \mu \mathrm{L}$ of complete ELISPOT medium were added to each well, followed by incubation for 2 hours at $37^{\circ} \mathrm{C}$. Target cells $\left(5 \times 10^{4}\right.$ cells $/ 50 \mu \mathrm{L}$ of complete ELISPOT medium) were then added to each well and the plates were incubated for 20 hours at $37^{\circ} \mathrm{C}$. After incubation, the plates were washed with PBS and $0.05 \%$ Tween 20 (Sigma). A biotinylated anti-rat IgG antibody (Mabtech) was diluted to $1 \mu \mathrm{g} / \mathrm{mL}$ in PBS $/ 0.5 \%$ bovine serum albumin, and $100 \mu \mathrm{L}$ was added to each well. The plates were incubated for 2 hours at $37^{\circ} \mathrm{C}$ and washed with PBS/0.05\% Tween 20. After washing, $100 \mu \mathrm{L}$ of avidin-enzyme complex (Vector Laboratories, Burlingame, Calif) was added to each well and incubated for 1 hour at room temperature. The plates were then washed and treated with $100 \mu \mathrm{L}$ of 3-amino-9-ethylcarbazole substrate (Sigma) and incubated for 4 minutes at room temperature, followed by rinsing with water to stop the reaction. The plates were then analyzed with the KS ELISPOT Automated Reader System (Carl Zeiss, Chester, Va).

\section{Evaluation of in Vivo MHC Class I Expression} Modulation on the Antitumor Properties of AdCD40L B16.F10 tumor cells $\left(5 \times 10^{5}\right.$ cells in $100 \mu \mathrm{L}$ of PBS $)$ were injected into the right flanks of C57BL/6 mice. When the tumor growth reached 45 to $50 \mathrm{~mm}^{2}$, treatment with PBS, AdNull, or AdCD40L $\left(5 \times 10^{10}\right.$ particles $)$ was administered intratumorally in $100 \mu \mathrm{L}$ of PBS. Additional mice received a single dose of IP rmIFN $\gamma$ alone (5000 U), with AdNull, or with AdCD40L. The size of the flank tumors was assessed every 2 to 3 days by measuring the largest perpendicular diameters using microcalipers and were recorded as an average tumor area $\left(\mathrm{mm}^{2}\right)$. When the animals appeared moribund or the tumor growth exceeded $15 \mathrm{~mm}$ in the largest diameter, the mice were killed and this time point was defined as date of death for survival analysis.

\section{Evaluation of MHC Class I Blockade with MHC Class I MAb in Vivo}

To assess the role of MHC class I expression enhancement by IFN $\gamma$ in vivo, tumor-bearing mice receiving intratumoral AdCD40L $\left(5 \times 10^{10}\right.$ particles $)$ and IP IFN $\gamma(5000 \mathrm{U})$ were treated with 3 successive intratumoral injections of mouse anti-mouse $\mathrm{H}-2 \mathrm{~Kb}$ MAb (20 $\mu \mathrm{g} / 100 \mu \mathrm{L}$ PBS; Sigma) on days 8 to 10 after tumor injection. Untreated mice and mice treated with AdCD40L 


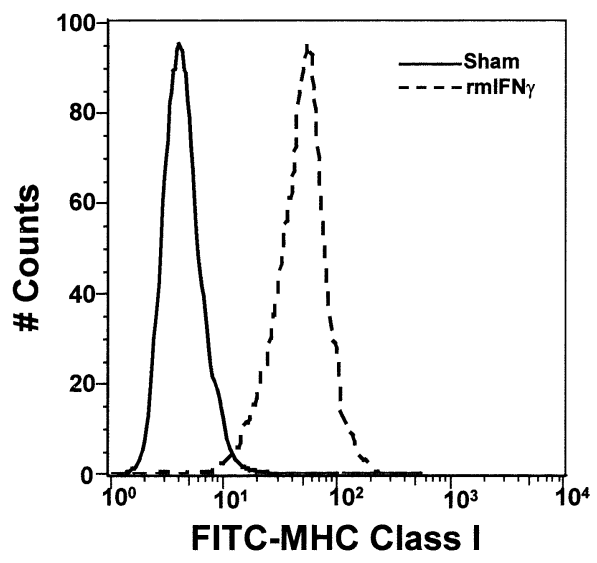

Figure 1. Exposure of B16.F10 cells to $\mathrm{rmIFN} \gamma$ in vitro increases H-2Kb MHC class I expression. B16.F10 cells were exposed to 500 $\mathrm{U} / \mathrm{mL}$ of $\mathrm{rmIFN} \boldsymbol{\gamma}$ for 48 hours, followed by staining with FITClabeled mouse anti-mouse $\mathrm{H}-2 \mathrm{~Kb}$ MAb or an isotype-matched control antibody, and subjected to flow cytometry; $0.42 \%$ of untreated B16.F10 cells bound the fluorescent label, compared with $95 \%$ of B16.F10 cells that had been exposed to rmIFN $\gamma$. The experiment shown represents 1 of multiple performed.

and IFN $\gamma$ served as controls. The size of the flank tumors was assessed every 2 days by measuring the largest perpendicular diameters using microcalipers and were recorded as an average tumor area $\left(\mathrm{mm}^{2}\right)$. A subset of mice from each group were killed 7 days after AdCD40L and IFN $\gamma$ injection and the spleens were harvested. The frequencies of tumor-specific CTLs were then evaluated using the ELISPOT assay as previously described.

\section{Statistical Analysis}

All data are reported as the mean \pm SEM unless otherwise specified. Statistical significance between means was determined using the unpaired, 2-tailed Student $t$ test. Survival evaluation was performed using the Kaplan-Meier analysis ( $P$ values were determined by Breslow test for significance).

\section{Results}

Exposure of B16.F10 Cells to rmIFN $\gamma$ Enhances MHC Class I Expression in Vitro

The effect of rmIFN $\gamma$ on the expression of MHC class I was determined by incubating B16.F10 cells with $500 \mathrm{U} / \mathrm{mL}$ of rmIFN $\gamma$ for 48 hours. B16.F10 cells exposed to $500 \mathrm{U} / \mathrm{mL}$ of rmIFN $\gamma$ demonstrated significantly enhanced expression of MHC class I molecules compared with naive B16.F10 cells (Figure 1). Of the B16.F10 cells treated with $\operatorname{rmIFN} \gamma$, 95\% expressed MHC class I while naive B16.F10 cells did not show any detectable expression. B16.F10 cells exposed to $\operatorname{rmIFN} \gamma$ and stained with an isotype-matched control antibody did not demonstrate any detectable MHC class I expression (data not shown).
Treatment of B16.F10 Tumor-Bearing Mice with a Single Dose of rmIFN $\gamma$ Enhances MHC Class I Expression in Vivo

To determine if rmIFN $\gamma$ would enhance expression of MHC class $\mathrm{I}$ in established B16.F10 tumors in vivo, tumor-bearing mice were injected with a single IP dose of rmIFN $\gamma$ $(5000 \mathrm{U})$. The tumors from mice receiving $\operatorname{rmIFN} \gamma$ uniformly expressed the $\mathrm{H}-2 \mathrm{~Kb}$ MHC class I antigen at both 24 and 48 hours following administration of the cytokine (Figure $2, A$ and $B$ ). B16.F10 tumors from untreated mice expressed low levels of $\mathrm{H}-2 \mathrm{~Kb}$ MHC class I (Figure 2, $C$ ). There was also no detection of $\mathrm{H}-2 \mathrm{~Kb}$ antigen in B16.F10 tumors that were stained with the isotype-matched control antibody (not shown).

Exposure of B16.F10 Tumor Cells to rmIFN $\gamma$ Enhances Binding of CD8+ T Lymphocytes in Vitro The conjugate-formation assay was performed to establish the effect of rmIFN $\gamma$ on the ability of CD8 + CTLs to bind to tumor cells (a class I-mediated phenomenon). The CD8+ CTLs were able to bind B16.F10 cells more effectively if the tumor cells had been exposed to rmIFN $\gamma$ (Figure 3, B and $D$ ) compared with untreated tumor cells (Figure 3, A and $D ; P=.002$ ). Furthermore, the addition of an MAb that binds MHC class I to these reaction conditions clearly inhibited the binding of CTLs to target cells (Figure 3,C and $D ; P=.007$, rmIFN $\gamma$-exposed cells incubated with $\mathrm{H}-2 \mathrm{~Kb}$ MHC class I MAb vs rmIFN $\gamma$-exposed cells alone).

\section{Prior Exposure of Target Tumor Cells to $\mathrm{rmIFN} \gamma$ in Culture Enhances Tumor-Specific Cytotoxic T- Lymphocyte Activation in Vitro}

Because the class I-mediated binding of CTLs (effector cells) to tumor cells (target cells) results in activation of the bound $\mathrm{T}$ cells, ${ }^{21-23}$ we sought to determine whether the enhanced binding induced by $\operatorname{rmIFN} \gamma$ exposure between these cells would augment CTL activation. To accomplish this, splenocytes from B16.F10 tumor-bearing mice that received intratumoral PBS, AdNull, or AdCD40L were harvested and incubated in vitro with untreated B16.F10 cells, B16.F10 cells exposed to $\operatorname{rmIFN} \gamma$, or LLC negative control cells for 20 hours in anti-IFN $\gamma$ MAb-coated 96-well plates (ELISPOT assay). As an additional control, splenocytes were incubated in complete ELISPOT medium without tumor cells. When the effector cells (splenocytes) were obtained from AdCD40L-treated mice, previous exposure of the B16.F10 cells (target cells) to rmIFN $\gamma$ resulted in significantly greater frequencies of activated CTLs compared with stimulation with B16.F10 cells that had not been exposed to this cytokine (Figure 4, A; $P=.01$ ). As expected, minimal CTL activation was observed when splenocytes were obtained from untreated tumor-bearing mice (Figure 4, B), mice that received AdNull (Figure 4, C), or 

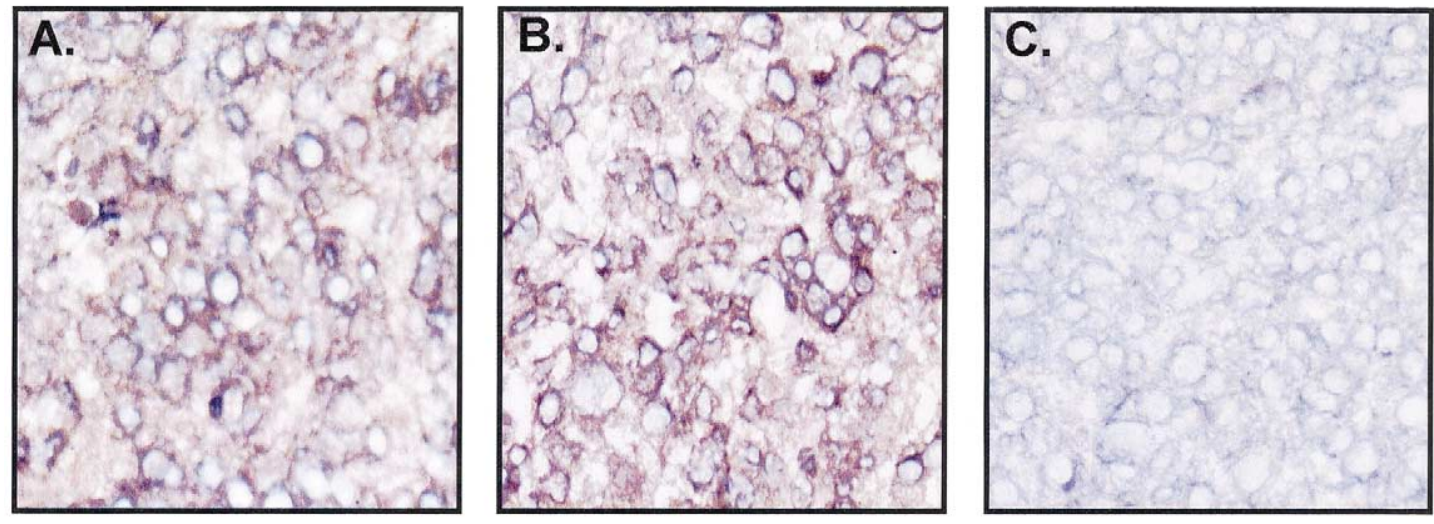

Figure 2. Intraperitoneal administration of rmIFN $\gamma$ enhances the expression of H-2Kb MHC class I by established B16.F10 flank tumors. B16.F10 tumors were established in C57BL/6 mice and rmIFN $\gamma(5000 \mathrm{U})$ was injected as a single IP dose. The tumors were resected 24 or 48 hours after rmIFN $\gamma$ administration and evaluated using immunohistochemistry. The dark brown surface membrane staining represents MHC class I expression. A, Twenty-four hours after rmIFN $\gamma$ treatment. B, Forty-eight hours after rmIFN $\gamma$ treatment. C, Tumor from an untreated mouse.

naive, tumor-free mice (Figure 4,D), regardless of the target cell type.

The Addition of a Single Dose of rmIFN $\gamma$ to an Active Immunotherapy Strategy Enhances Cytotoxic TLymphocyte Generation in the Tumor-Bearing Host Because MHC class I expression plays an integral role in the presentation of tumor antigens to naive $\mathrm{T}$ lymphocytes, we sought to determine whether up-regulating MHC class I expression by established tumors in vivo (using $\operatorname{rmIFN} \gamma$ ) would result in enhanced generation of tumor-specific CTLs when combined with an active immunotherapy strategy. To investigate this, B16.F10 tumor-bearing mice were either treated with intratumoral AdCD40L or AdNull or left untreated. A similar experiment was simultaneously conducted with the same groups, except that a single IP dose of rmIFN $\gamma$ was administered (5000 U). LLC cells served as control target cells. The relative frequency of CTLs was then assessed using the ELISPOT assay. Significantly greater frequencies of activated tumor-specific CTLs were obtained from the spleens of mice that had received both AdCD40L and rmIFN $\gamma$ when compared with AdCD40L alone (Figure 5; $P=.000004$ ) or any other treatment group. In addition, minimal CTL generation was observed in any group when LLC cells were used as targets (not shown).

\section{The Addition of a Single Dose of rmIFN $\gamma$ Enhances} the Antitumor Activity and Cure Rate of AdCD40L To determine whether the addition of a single dose of rmIFN $\gamma$ would augment the antitumor properties of AdCD40L in vivo, B16.F10 tumor-bearing mice were given intratumoral AdCD40L as well as IP $\operatorname{rmIFN} \gamma(5000 \mathrm{U})$ concomitantly. Additional groups of mice were treated with intratumoral PBS, AdNull, AdNull with IP $\operatorname{rmIFN} \gamma$, or IP rmIFN $\gamma$ alone. Tumor regression was more pronounced in the mice receiving AdCD40L and rmIFN $\gamma$ compared with mice receiving AdCD40L alone (Figure 6, $A ; P=.004$ ), AdNull $(P=.001)$, rmIFN $\gamma$ alone $(P=.0004)$, AdNull with $\operatorname{IFN} \gamma(P=.001)$, or PBS $(P=.0000004)$. In addition, the cure rate observed with the combination of AdCD40L and $\operatorname{rmIFN} \gamma$ was superior to that of any other group (Figure $6, B ; P=.01$ vs AdCD40L alone; $P=.008$ vs AdNull; $P$ $=.0017$ vs AdNull plus rmIFN $\gamma ; P=.0017$ vs rmIFN $\gamma$ alone; $P=.0018$ vs PBS).

\section{Blockade of MHC Class I in Vivo Attenuates the Synergistic Effect of rmIFN $\gamma$ on the Antitumor} Activity and CTL Generation Induced by AdCD40L

To dissect the role of enhanced MHC class I expression in the synergistic effect of rmIFN $\gamma$ on tumor regression and CTL generation induced by AdCD40L, 3 successive intratumoral injections of MHC class I MAb were administered. The extent of tumor regression was significantly greater in mice treated with AdCD40L and $\operatorname{rmIFN} \gamma$ compared with mice receiving AdCD40L, IFN $\gamma$, and MHC class I MAb (Figure 7, $A ; P=.007$ ) or PBS alone (Figure 7, $A ; P=$ $.00001)$. This effect persisted for 6 days after the initial intratumoral injection of MHC class I MAb, after which time regression rates became similar between the 2 groups receiving AdCD40L. In addition, the enhanced CTL generation afforded by rmIFN $\gamma$ was significantly diminished in the animals that received MAb blockade (Figure 7, $B ; P=$ .016 , AdCD40L, rmIFN $\gamma$ vs AdCD40L, rmIFN $\gamma$ plus anticlass I MAb). Finally, minimal stimulation was observed in any group when LLC cells were used as targets (not shown). 
A. Untreated B16

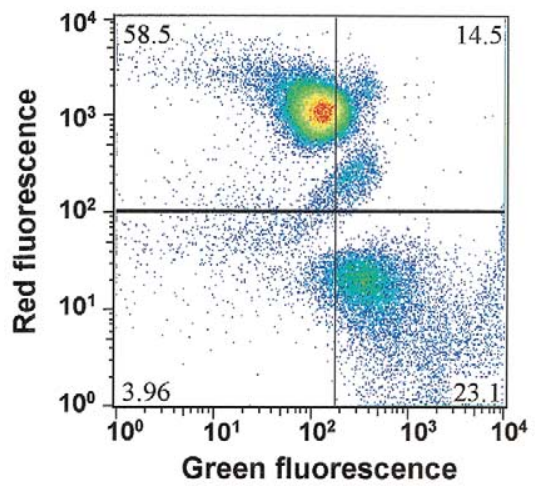

C. $B 16+$ rmIFN $\gamma+$ MHC-I MAb

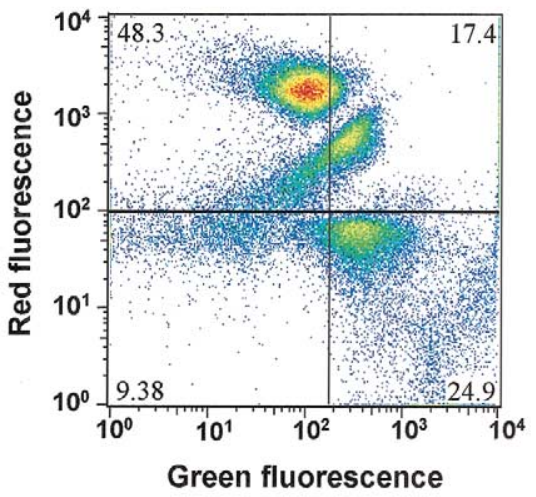

B. B16 + rmIFN $\gamma$

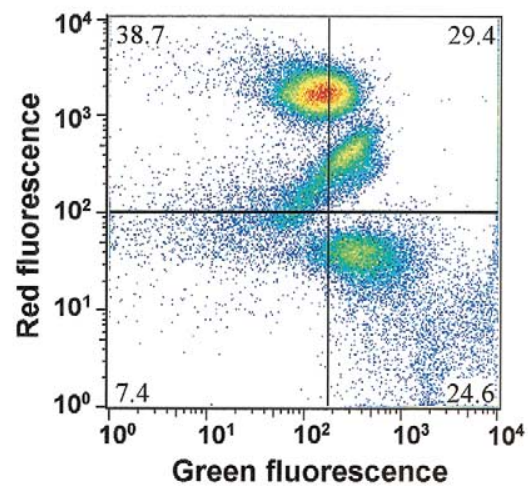

D. Summary

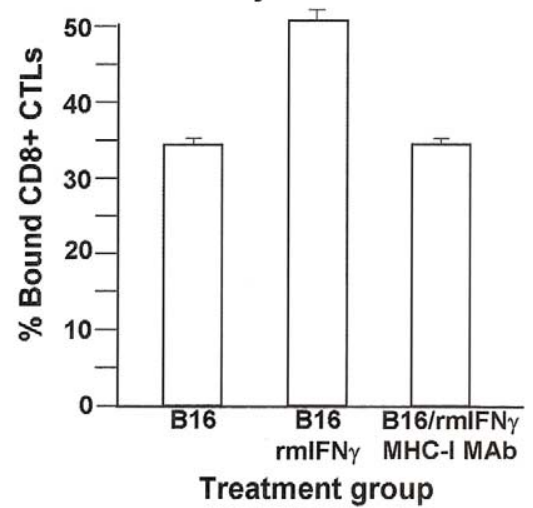

Figure 3. Up-regulation of H-2Kb MHC class I expression enhances the binding of CD8+ CTLs to B16.F10 tumor cells in a conjugate-formation assay. Naive B16.F10 cells or rmIFN $\gamma$-exposed B16.F10 cells were stained with hydroethidine (red), and tumor-specific CD8+ CTLs were stained with sulfofluoresceindiacetate (green). The 2 cell populations were then cocultured and subjected to 2-color flow cytometry. The binding of CD8+ CTLs and B16.F10 cells is defined as the double positive population in the right upper quadrant. $A$ to $C$, Cytograms from a representative experiment of 3 independent experiments. A, Naive B16.F10 cells cocultured with CD8+ CTLs. B, rmIFN $\gamma$-exposed B16.F10 cells cocultured with CD8+ CTLs. C, rmIFN $\gamma$-exposed B16.F10 cells cocultured with CTLs and anti-MHC class I MAb. D, Summary data from 3 separate experiments performed. The $\%$ binding is defined as: Binding $(\%)=($ no. of green-red double positive cells)/(no. of green positive cells) $\times 100$. Each bar represents the mean \pm SEM.

\section{Discussion}

Lung cancer is responsible for more cancer deaths than any other malignant tumor in the United States. ${ }^{24}$ Fewer than $15 \%$ of patients presenting with lung cancer will ever be cured of their disease, with the vast majority of patients succumbing to distant metastasis, ${ }^{24}$ implying that more effective systemic therapy is a priority for these patients. Augmentation of antitumor immunity represents a treatment strategy that has the potential to be both tumor-specific as well as systemic in nature; however, reports describing its use for patients with lung cancer have not conclusively demonstrated efficacy. ${ }^{25}$ The antitumor immune response has traditionally been divided into afferent (stimulatory) and efferent (effector) limbs, with MHC class I molecules playing an integral role in both limbs. ${ }^{1-3}$ One mechanism by which tumor cells may evade the immune response is by down-regulating the expression of MHC class I on their surface, a process that could potentially interfere with both CTL generation (afferent limb) as well as subsequent recognition and binding of CTLs to target tumor cells (effector limb). This phenomenon is evident in human lung cancer cell lines, where as many as $33 \%$ to $43 \%$ have lost MHC class I expression. ${ }^{4,7,10}$ In our laboratory, which is focused on the use of gene transfer to induce antitumor immunity, we have observed that active immunotherapy strategies are significantly less effective in murine tumor models that express little or no MHC class I, exemplified by the metastatic variant of the B16 melanoma, B16.F10. ${ }^{11,12}$ Given this information, the purpose of the present study was to determine whether MHC class I expression could be en- 


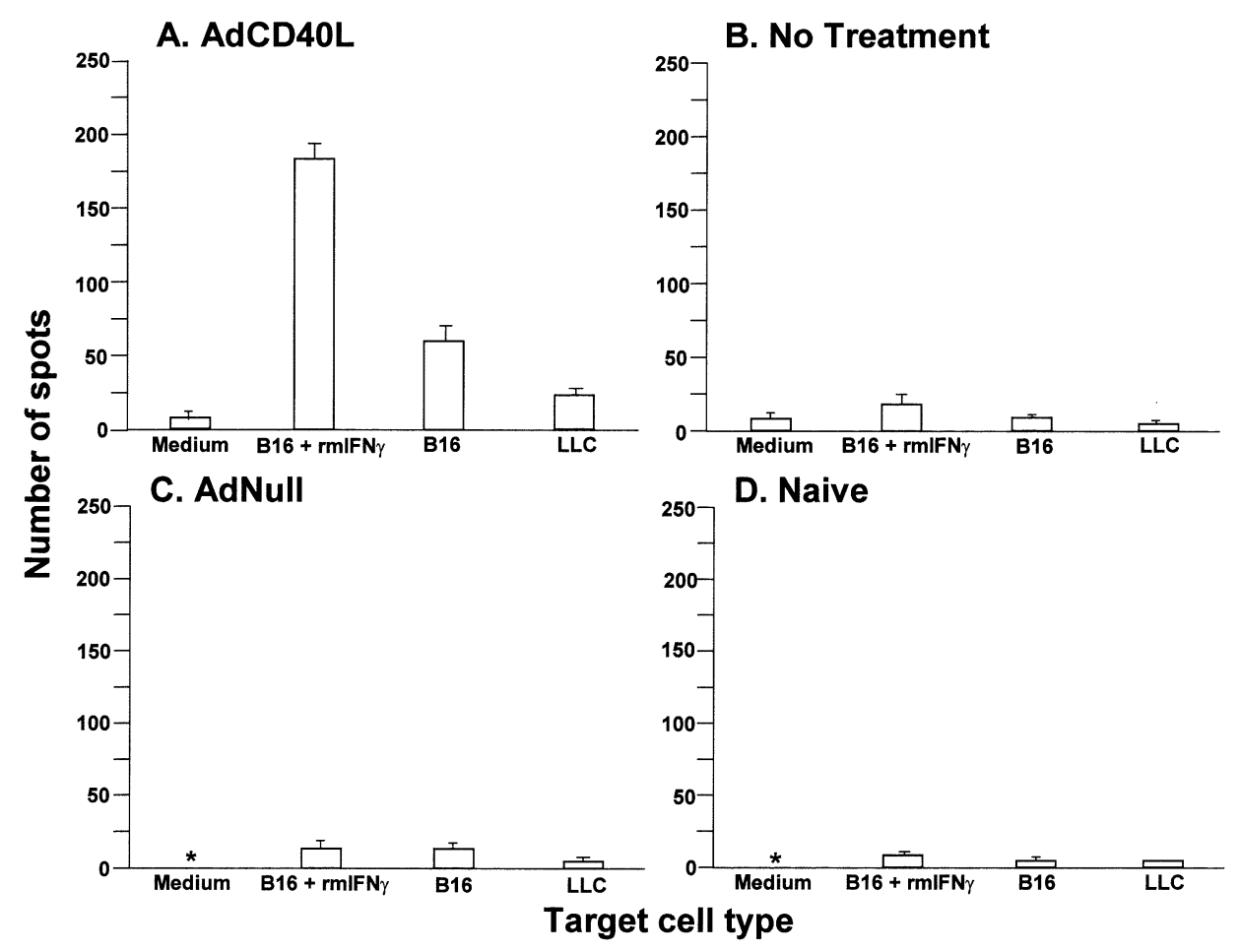

Figure 4. Pretreatment of B16.F10 cells with rmIFN $\gamma$ results in more efficient stimulation of tumor-specific CTLs in vitro. CTLs were harvested from mice and evaluated for IFN $\gamma$ release (activation) in the ELISPOT assay as described in Materials and Methods. Each bar represents the mean number of spots \pm SEM from a total of 3 wells from each group. A, Splenocytes from AdCD40L-treated, tumor-bearing mice. B, Splenocytes from tumor-bearing mice receiving no treatment. C, Splenocytes from AdNull-treated, tumor-bearing mice. D, Splenocytes from untreated, tumor-free mice. *No spots detected.

hanced on B16.F10 cells and whether this up-regulation would result in (1) more efficient tumor-specific CTL generation in tumor-bearing mice (afferent limb) and (2) more efficient tumor cell-induced binding and activation of tumor-specific CTLs (efferent limb). The data show that MHC class I expression by B16.F10 cells is readily enhanced by exposure to the murine cytokine, $\operatorname{rmIFN} \gamma$, in vitro and in vivo, and that this up-regulation results in more efficient binding of tumor-specific CTLs to B16.F10 cells. Furthermore, a single dose of rmIFN $\gamma$ enhances the generation of CTLs by tumor-bearing mice (afferent limb) and augments the antitumor effect and cure rate observed with an established active immunotherapy strategy (AdCD40L). Finally, B16.F10 cells that have been exposed to rmIFN $\gamma$ are more potent activators of CTLs than tumor cells that have been exposed to this cytokine.

Enhancement of the Afferent Limb of the Antitumor Immune Response by a Single Dose of rmIFN $\gamma$ The afferent limb of the antitumor immune response involves presentation of tumor-associated antigens to naive CD8 + T lymphocytes, a process that requires MHC class I expression by tumor cells. ${ }^{1-3}$ With the addition of costimu-

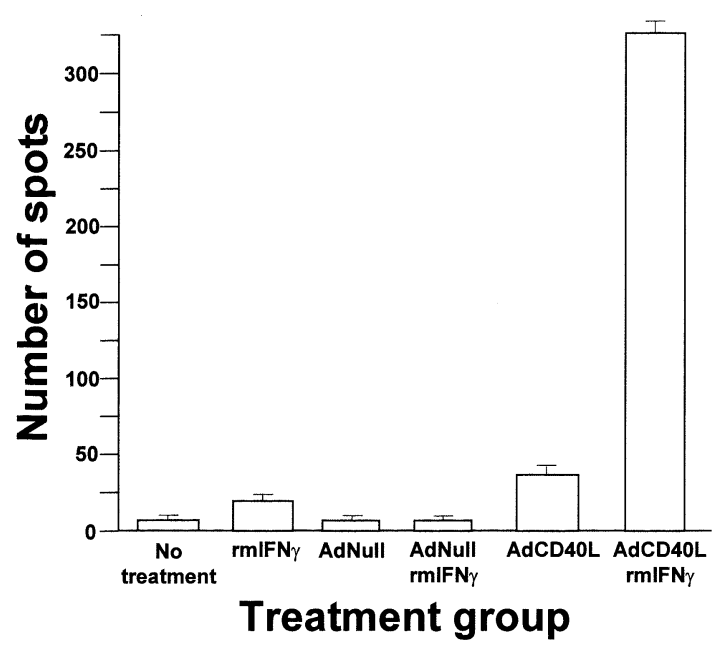

Figure 5. In vivo administration of a single dose of $\operatorname{rmIFN} \gamma$ to tumor-bearing mice enhances tumor-specific CTL generation induced by AdCD40L. CTLs were harvested from tumor-bearing mice and evaluated for IFN $\gamma$ release (activation) using the ELISPOT assay as described in Materials and Methods. Each bar represents the mean number of spots \pm SEM from a total of 3 wells for each group. Target cells for this experiment consisted of only untreated B16.F10 tumor cells. 
A. Tumor Area

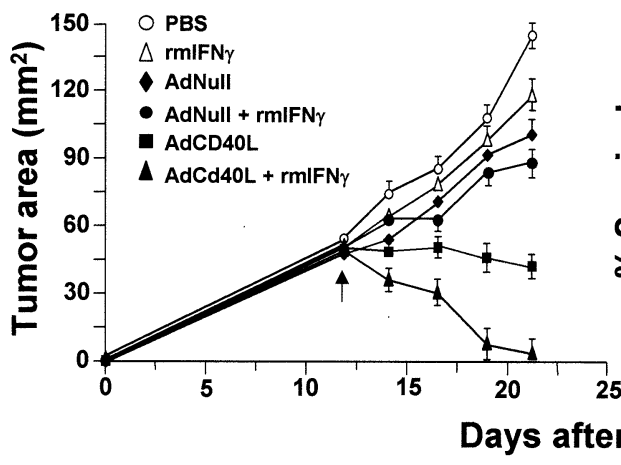

B. Survival

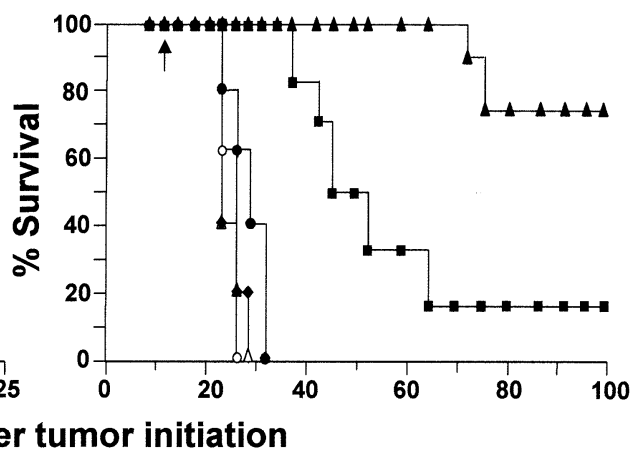

Figure 6. A single dose of rmIFN $\gamma$ enhances the antitumor effect and cure rate obtained with intratumoral injection of AdCD40L. Twelve days after B16.F10 flank tumor initiation, C57BL/6 mice were randomized to 6 groups: AdCD40L plus IP rmIFN $\gamma(n=6)$; AdCD40L alone $(n=6)$; AdNull plus IP rmIFN $\gamma(n=6)$; AdNull alone $(n=5) ;$ IP rmIFN $\gamma$ alone $(n=5)$; or PBS $(n=5)$. All vectors were administered intratumorally $\left(5 \times 10^{10}\right.$ particle units/100 $\mu L$ of PBS), and mIFN $\gamma(5000 \mathrm{U})$ was administered concomitantly with the adenovirus vectors. The tumor area was assessed at 2- to 3-day intervals with microcalipers. The data points represent the mean tumor area + SEM. The mice were killed when the largest tumor diameter reached $15 \mathrm{~mm}$. A, Tumor area. B, Survival. The arrows indicate the day of treatment.

lation, these $\mathrm{T}$ cells are then able to differentiate into tumorspecific CTLs, proliferate, and circulate throughout the body. In this regard, AdCD40L is an adenovirus gene transfer vector encoding the murine CD40 ligand cDNA and has been demonstrated to augment the afferent limb of the antitumor immune response by generating tumor-specific CTLs when administered intratumorally in mice, resulting in regression of established tumors. ${ }^{11}$ Tumor regression and cure rates are limited, however, when this vector is used to treat murine tumors that express little or no MHC class I (eg, B16.F10). ${ }^{11}$ As a strategy to augment the antitumor effect of AdCD40L when used to treat MHC class I-deficient tumors, we sought to up-regulate MHC class I expression on established tumors in vivo using $\operatorname{rmIFN} \gamma$, a cytokine known to modulate MHC class I expression by many tumor cell types in vitro. ${ }^{8,10,26}$ Interestingly, only a single dose of systemic rmIFN $\gamma$ was necessary to markedly enhance MHC class I expression by established B16.F10 tumors in vivo. Furthermore, the data show that the same dose of rmIFN $\gamma$ had virtually no antitumor effect or CTL-generating ability on its own in this model. When combined with AdCD40L, however, rmIFN $\gamma$ induced pronounced augmentation of both the antitumor response and cure rate, as well as CTL generation induced by this vector. The observation that intratumoral injection of a class I antibody partially abrogated the CTL response in this model suggests that the class I-modulating properties of IFN $\gamma$ are responsible for its synergistic effects. However, this direct cause-and-effect relationship cannot be stated with certainty as CD40 ligation itself has been shown to up-regulate class I expression on some carcinomas. ${ }^{27}$ Complete abrogation was not observed in this experiment most likely because the antibody was administered only on 3 days, allowing the synergistic antitumor effects of IFN $\gamma$ to emerge by the time the spleens were harvested for the ELISPOT assay (7 days posttreatment). Only 3 doses of antibody were used for these experiments for 2 reasons. First is the high cost of the antibody. Second, in the tumor size experiment (Figure 7, A), it was desired to temporarily block class I, show a significant difference in tumor size, then withdraw the antibody to demonstrate dissipation of this difference.

\section{Enhancement of the Efferent Limb of the Antitumor Immune Response by a Single Subtherapeutic Dose of rmIFN $\gamma$}

The efferent limb of the antitumor immune response is invoked when antigen-specific, differentiated CTLs reencounter tumor cells expressing the original tumor-associated antigens. The CTLs then bind to the tumor cell via interaction between MHC class I and the CD8 + T-cell receptor, resulting in activation of the CTL, cytokine release, and initiation of the apoptotic cascade in the bound tumor cell. ${ }^{1-3}$ Given the vital role of MHC class I in CTL binding and activation in the efferent limb, we sought to determine whether prior exposure of target tumor cells to rmIFN $\gamma$ would make these processes more efficient based on the ability of this cytokine to up-regulate MHC class I expression. The present study suggests that this is true and is supported by the following observations. First, although CTLs from AdCD40L-treated mice bind target B16.F10 cells in vitro, this binding is significantly more pronounced if the tumor cells are pretreated with $\operatorname{rmIFN} \gamma$. Second, this 


\section{A. Tumor Size}

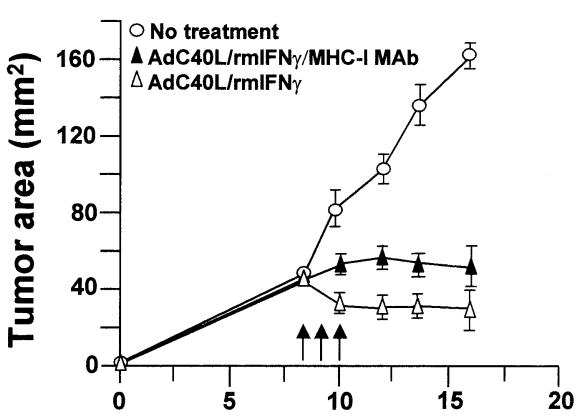

Days after tumor initiation
B. CTL Generation

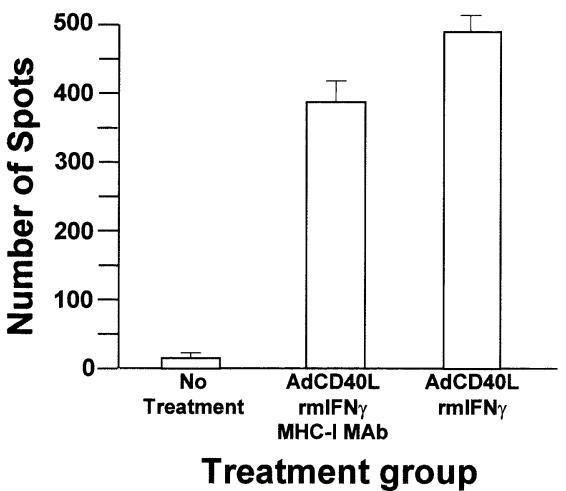

Figure 7. Intratumoral MAb blockade of MHC class I attenuates the synergistic effect of rmIFN $\gamma$ on antitumor immunity induced by AdCD40L. Eight days after B16.F10 flank tumor initiation, mice were randomized to 3 groups: intratumoral AdCD40L plus IP rmIFN $\gamma$, intratumoral AdCD40L plus IP rmIFN $\gamma$ plus 3 successive intratumoral injections of an anti-MHC class I MAb $(20 \mu \mathrm{g})$, or no treatment. Mice were followed over time for measurement of tumor area. In addition, mice from each group were killed 7 days after treatment for splenocyte harvest and evaluation of CTL generation using the ELISPOT assay as previously described. A, Tumor area. Each arrow represents 1 intratumoral injection of anti-MHC class I MAb. B, CTL generation using the ELISPOT assay. Each bar represents the mean number of spots \pm SEM of 3 wells performed for each group.

enhanced binding induced by $\operatorname{rmIFN} \gamma$ is abrogated by the addition of an anti-MHC class I MAb to the reaction conditions. Finally, the proportion of tumor-specific CTLs that are activated by exposure to B16.F10 tumor cells in the ELISPOT assay is markedly increased by pretreatment of the tumor cells with rmIFN $\gamma$, confirming that the up-regulated MHC class I is indeed a functional receptor.

\section{Clinical Implications of MHC Class I Expression Modulation}

Given the relative lack of significant antitumor responses in clinical immunotherapy trials ${ }^{25,28}$ and the common observation that human tumors seem to down-regulate $\mathrm{MHC}$ class I expression to evade the immune response, enhancement of MHC class I expression to augment CTL generation represents a valid approach to enhance the antitumor immune response induced by clinical immunotherapeutic strategies. IFN $\gamma$ is a reasonable agent to investigate in this regard because (1) its ability to enhance MHC class I expression in multiple tumor types in vitro is reasonably well characterized ${ }^{8,10,26}$; (2) the data from the present study suggest that it may be used in this capacity at a low, subtherapeutic, nontoxic dose; and (3) its toxicity profile has already been elucidated in humans. ${ }^{29}$ Despite these advantages, some tumor cell lines are unresponsive to the class I-modulating properties of IFN $\gamma{ }^{8}$ As a result, further investigation regarding both the mechanism of class I upregulation, as well as other modulating agents, is warranted.

\section{References}

1. Agrawal S, Kishore MC. MHC class I gene expression and regulation. J Hematother Stem Cell Res. 2000;9:795-812.

2. Rees RC, Mian S. Selective MHC expression in tumors modulates adaptive and innate antitumor responses. Cancer Immunol Iтmиnother. 1999;48:374-81.

3. Tanaka K, Yoshioka T, Bierberich C, Jay G. Role of the major histocompatibility complex class I antigens in tumor growth and metastasis. Аппи Rev Immunol. 1988;6:359-80.

4. Hiraki A, Kaneshige T, Kiura K, Ueoka H, Yamane H, Tanaka M, et al. Loss of HLA haplotype in lung cancer cell lines: implications for immunosurveillance of altered HLA class I/II phenotypes in lung cancer. Clin Cancer Res. 1999;5:933-6.

5. Korkolopoulou P, Kaklamanis L, Pezzella F, Harris AL, Gatter KC. Loss of antigen-presenting molecules (MHC class I and TAP-1) in lung cancer. Br J Cancer. 1996;73:148-53.

6. Dammrich J, Muller-Hermelink HK, Mattner A, Buchwald J, Ziffer S. Histocompatibility antigen expression in pulmonary carcinomas as indication of differentiation and special subtypes. Cancer. 1990;65: 1942-54.

7. Sugaya M, Takenoyama M, Osaki T, Yasuda M, Nagashima A, Sugio $\mathrm{K}$, et al. Establishment of 15 cancer cell lines from patients with lung cancer and the potential tools for immunotherapy. Chest. 2002;122: 282-8.

8. Wroblewski JM, Bixby DL, Borowski C, Yannelli JR. Characterization of human non-small cell lung cancer (NSCLC) cell lines for expression of MHC, co-stimulatory molecules and tumor associated antigens. Lung Cancer. 2001;33:181-4.

9. AbdAlla EE, Blair GE, Jones RA, Sue-Ling HM, Johnston D. Mechanism of synergy of levamisole and fluorouracil: induction of human leukocyte antigen class I in a colorectal cancer cell line. J Natl Cancer Inst. 1995;87:489-96.

10. Yano T, Fukuyama Y, Yokoyama H, Kuninaka S, Asoh H, Katsuda Y, et al. HLA class I and class II expression of pulmonary adenocarcinoma cells and influence of interferon gamma. Lung Cancer. 1998; 20:185-90

11. Kikuchi T, Crystal RG. Anti-tumor immunity induced by in vivo 
adenovirus vector-mediated expression of CD40 ligand in tumor cells. Hum Gene Ther. 1999;10:1375-87.

12. Lee JA, Mahtabifard A, Yamada R, Crystal RG, Korst RJ. Adenovirus vector-mediated overexpression of a truncated form of the p65 nuclear factor $\kappa \mathrm{B}$ cDNA in dendritic cells enhances their function resulting in immune-mediated suppression of preexisting murine tumors. Clin Cancer Res. 2002;8:3561-9.

13. Hersh JR, Crystal RG, Bewig B. Modulation of gene expression after replication deficient, recombinant adenovirus-mediated gene transfer by the product of a second adenovirus vector. Gene Ther. 1995;2:124-31.

14. Rosenfeld MA, Yoshimura K, Trapnell BC, Yoneyama K, Rosenthal $\mathrm{ER}$, Dalemans W, et al. In vivo transfer of the human cystic fibrosis transmembrane conductance regulator gene to airway epithelium. Cell. 1992;68:143-55.

15. Rosenfeld MA, Sigfried W, Yoshimura K, Yoneyyama K, Fukayama $\mathrm{M}$, Stier LE, et al. Adenovirus-mediated transfer of a recombinant alpha1-antitrypsin gene to the lung epithelium in vivo. Science. 1991; 252:431-4.

16. Mittereder N, March KL, Trapnell BC. Evaluation of the concentration and bioactivity of adenovirus for gene therapy. J Virol. 1996;70:7498-509.

17. Nakamura T, Takahashi K, Koyanagi M, Yagita H, Okumura K. Activation of a natural killer clone upon target cell binding via $\mathrm{CD} 2$. Eur J Immunol. 1991;21:831-4.

18. Noguchi K, Tanimura H, Yamaue H, Iwahashi M, Tsunoda T, Tani M, et al. Enhancement of tumor cell susceptibility to tumor-infiltrating lymphocytes by cisplatin. J Cancer Res Clin Oncol. 1997;123:345-51.

19. Lewis J, Janetzki S, Schaed S, Panageas KS, Wang S, Williams L, et al. Evaluation of CD8 $+\mathrm{T}$ cell frequencies by the ELISPOT assay in healthy individuals and in patients with metastatic melanoma immunized with tyrosinase peptide. Int J Cancer. 2000;87:391-8.

20. Scheibenbogen C, Romero P, Rivoltini L, Herr W, Schmittel A, Cerottini J-C, et al. Quantitation of antigen-reactive T cells in peripheral blood by IFN- $\gamma$-ELISPOT assay and chromium-release assay: a four-centre comparative trial. J Immunol Methods. 2000;244:81-9.

21. Doherty PC, Knowles BB, Wettstein PJ. Immunological surveillance of tumors in the context of major histocompatibility complex restriction of T cell function. Adv Cancer Res. 1984;42:1-65.

22. Hui KM. Re-expression of major histocompatibility complex (MHC) class I molecules on malignant tumor cells and its effect on host-tumor interaction. BioEssays. 1989;11:22-6.

23. Marrack P, Kappler J. The T-cell repertoire for antigen and MHC. Immunol Today. 1988;9:308-15.

24. Greenlee RT, Murray T, Bolden S, Wingo PA. Cancer statistics, 2000. CA Cancer J Clin. 2000;50:7-33.

25. Hollinshead A, Stewart TH, Takita H, Dalbow M, Concannon J. Adjuvant specific lung cancer immunotherapy trials. Tumor-associated antigens. Cancer. 1987;60:1249-62.

26. Blieden TM, McAdam AJ, Foresman MD, Cerosaletti KM, Frelinger FG, Lord EM. Class-I MHC expression in the mouse lung carcinoma, line 1: a model for class-I inducible tumors. Int J Cancer. 1999;6:82-9.

27. Yamada M, Shiroko T, Kawaguchi Y, et al. CD40-CD40 ligand (CD154) engagement is required but not sufficient for modulating MHC class I, ICAM-1 and Fas expression and proliferation of human non-small cell lung tumors. Int J Cancer. 2001;92:589-99.

28. Al-Moundhri M, O'Brien M, Souberbielle BE. Immunotherapy in lung cancer. Br J Cancer. 1998;78:282-8.

29. Gleave ME, Elhilali M, Fradet Y, Davis I, Vemer P, Saad F, et al. Interferon gamma-1b compared to placebo in metastatic renal-cell carcinoma. N Engl J Med. 1998;338:1265-71.

\section{Discussion}

Dr Dao D. Nguyen (Bethesda, Md). How toxic is IFN $\gamma$ injection to animals?
Dr Merritt. We gave a single intraperitoneal injection at the time that we gave an intratumoral injection of either AdCD40 ligand or the control vector.

Dr Nguyen. For future application, how do you envision using this strategy in human immunotherapy? I guess, and Dr Korst can correct me, if you're planning to develop this treatment for lung cancer, for example, which is very poor at expressing MHC class I, how do you plan to up-regulate class I expression?

Dr Merritt. Well, in terms of toxicity, it's already been worked out for IFN $\gamma$ in previous studies treating human renal cell carcinoma. We would essentially give an intratumoral injection of the AdCD40 ligand and then give intravenous IFN $\gamma$ at the time of therapy.

Dr Nguyen. Are you planning to use all the pharmacologics that might up-regulate for MHC class I? We have done that before using a drug like decitabine, which is a demethylating agent, and there is increase in expression of class I in the culture lung cancer cell lines. Do you have any plan of using all the strategies besides IFN $\gamma$ used to up-regulate the MHC class I expression?

Dr Merritt. No. Initially we would start with giving intravenous IFN $\gamma$ in combination with our adenoviral gene transfer vector to see if we could get efficacy. That would be the initial experiment.

Dr Richard J. Battafarano (St Louis, Mo). It's pretty clear that you need class I expression for your CTLs to lyse the tumor cells. But really, what your data shows is that you need class I expression to actually generate the immune response, I assume through your dendritic cells, because the CD40 ligand would enhance the dendritic cells. Why do you think class I expression is so important on the tumors at the time that you're generating the immune response? It's clear why it would be important at the time you're trying to lyse the tumor cells. Why do you think class I expression is important then?

Dr Merritt. In previous studies where the AdCD40 ligand was used as a monotherapy, there was actually an antitumor response that was demonstrated in mirroring cell lines that were immunogenic and that expressed MHC class I. And in the murine cancer lines that did not express class $\mathrm{I}$, there was a less effective antitumor effect. We think that the IFN $\gamma$ is augmenting the MHC class I up-regulated on the immunogenic cell lines, therefore making these cells more susceptible to CTL-mediated cell lysis.

Dr Battafarano. But do you think that there is something else being up-regulated, that there is some other tumor antigen that might be being up-regulated in there, and that's really what the dendritic cells are processing?

Dr Merritt. Do you mean in terms of costimulatory molecules? It would be hard for us to ascertain that based on just this study alone. But it is a possibility.

Dr Robert J. Korst (New York, NY). The Achilles' heel of this strategy is that it is hard to predict which tumors will be refractory to IFN gamma, and which will upregulate class I with other agents, including retinoids. Also, the exact mechanism behind this upregulation is unclear. 